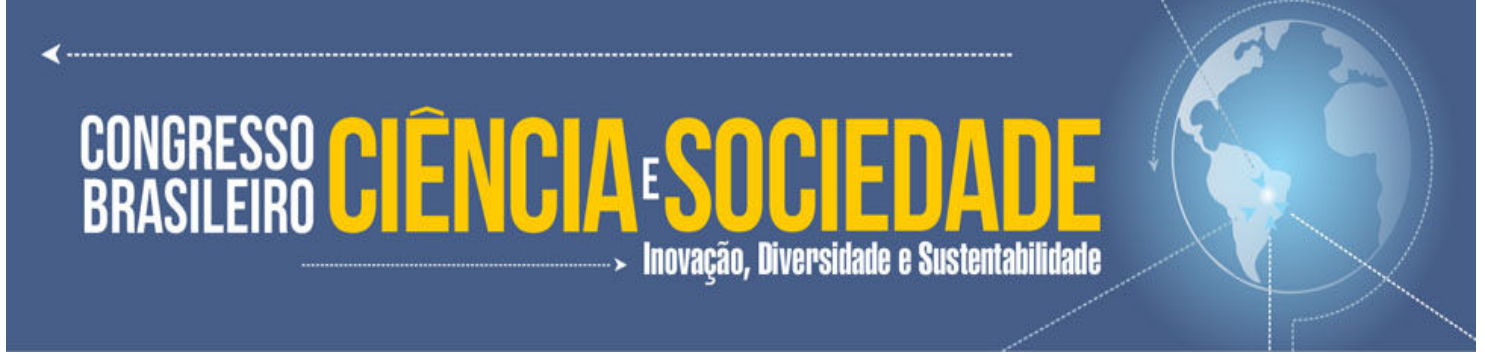

\title{
A ASSISTÊNCIA SOCIAL NO CONTEXTO DO SUAS E A IMPORTÂNCIA DA GARANTIA DOS DIREITOS SOCIOASSISTENCIAIS PARA O EXERCÍCIO DA CIDADANIA $^{1}$
}

\author{
Maria Guadalupe de Araújo Veloso Lima Freitas - UFPI ${ }^{2}$ \\ Rosilene Marques Sobrinho de França- UFPI
}

\section{RESUMO}

A Constituição Federal de 1988 garante a Política de Assistência Social como sendo de proteção social não contributiva, formando o tripé das políticas de Seguridade Social junto com a Saúde e a Previdência, elegendo-a como um dos mecanismos de enfrentamento da questão social. Nesse sentido, o trabalho traz uma discussão acerca dos direitos socioassistenciais no contexto do sistema de proteção social brasileiro e da política de Assistência Social. A metodologia utilizada consistiu em estudo bibliográfico e documental acerca da trajetória dos direitos fundamentais do homem e a construção da cidadania, examinando-se a formatação dos direitos socioassistenciais e seus desdobramentos no âmbito da política de Assistência Social. Os resultados mostraram que os direitos socioassistenciais são fundamentais para a construção de uma sociedade mais justa e igualitária.

Palavras-chave: Direitos Socioassistenciais. Proteção Social. Política de Assistência Social.

\section{ABSTRACT:}

The federal Constitution of 1988 guarantees the Social Assistance policy as a social protection policy non-contributory, one of the three policies of the Social Security together with Health and Welfare, choosing it as one of the coping mechanisms of the social issue. In this sense, the paper presents a discussion about the social-assistance rights on the background of the Brazilian Social Protection System and in the Social Assistance Policy. The methodology is based on a bibliographical and documentary study about the history of fundamental human rights and the citizenship creation, examining the social assistance rights development and their unfolding within the scope of the Social Assistance Policy. The results have shown that progress was made in the Social Assistance Policy and the social-assistance rights are fundamental for a more just and egalitarian society.

KEYWORDS: Social-assistance rights. Social Protection. Social Assistance Policy.

\footnotetext{
${ }^{1}$ Trabalho apresentado no Congresso Brasileiro Ciência e Sociedade (CBCS 2019), promovido pelo Centro Universitário Santo Agostinho, de 03 a 05 de outubro de 2019, em Teresina-PI.

${ }^{2}$ Especialista na Área de Violência Doméstica contra Crianças e Adolescentes pela Universidade de São Paulo (USP). Especialista na área de Gestão de Cidades pela Fundação Getúlio Vargas (FGV). Estudante do Programa de Pós-Graduação em Políticas Públicas da Universidade Federal do Piauí (UFPI). Teresina-PI/Brasil.E-mail:guadalupeveloso@hotmail.com.

Doutora em Políticas Públicas. Docente do Curso de Serviço Social e do Programa de Pós-Graduação em Políticas Pública da Universidade Federal do Piauí (UFPI). E-mail:rosilenemarquessobrinho@gmail.com.
} 


\section{moNPESSSOCFENCAESOCIEDADE

\section{INTRODUÇÃO}

A Política de Assistência Social como política pública nasce com a Constituição Federal de 1988. Assim pode-se dizer que nessa condição de política pública de Estado é um fato muito recente. Nessa ótica, a Assistência Social passa a compor o tripé da seguridade social do Brasil, e que têm como dever a proteção dos que dela necessitam e, tem como um dos grandes desafios para sua implementação o de romper com o ideário conservador na proteção social das pessoas mais necessitadas ainda persistente nos dias atuais.

Sabe-se que muitos autores, como Sonia Draibe (1993) e Marshall (1977), realizaram estudos sobre sistemas de proteção social, nos quais mostram que não existe sociedade que não tenha vivenciado qualquer tipo de proteção, a ponto de deixar os indivíduos a mercê da própria sorte quando estes porventura enfrentassem situações de risco, presentes nos contextos históricos. Ao contrário, sempre houve uma preocupação da sociedade em amparar as classes menos favorecidas, mesmo que esse reconhecimento acontecesse pela via do dever moral.

Destaca-se que, no âmbito das sociedades capitalistas, a constituição dos sistemas de proteção social está diretamente associada aos diferentes modelos de organização e gestão do trabalho e aos diferentes processos de reprodução das relações sociais, que têm por especial agente o Estado.

O estudo tem como propósito analisar a política de Assistência Social, como uma política pública que visa promover o acesso aos direitos da população que dela necessitar e, consequentemente, de sua cidadania, em um contexto de desmonte dos direitos conquistados na atual sociedade brasileira.

Dessa forma, o artigo, inicialmente, apresenta um estudo introdutório sobre os direitos do homem e a formação de sua cidadania, posteriormente, aborda a questão do sistema de Proteção Social Brasileiro, seguida de um levantamento da trajetória da Assistência Social até chegar ao status de Política Pública, depois, faz uma abordagem sobre a questão dos direitos socioassistenciais como forma de implementação dessa 


\section{CONGRESSO

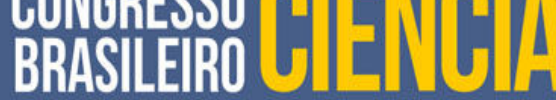

Política e, na conclusão, destaca algumas reflexões sobre a construção da referida política, que tem muitos desafios ainda a enfrentar.

\section{METODOLOGIA}

Visando uma maior familiaridade com tema ora em estudo a metodologia utilizada foi uma pesquisa exploratória com uma abordagem qualitativa. $\mathrm{O}$ procedimento metodológico utilizado foi estudo bibliográfico e documental. Segundo Gil, a pesquisa bibliográfica “é desenvolvida com base em material já elaborado, constituído principalmente de livros e artigos científicos" (GIL, 2002, p. 44). Quanto a pesquisa documental, para Gil (2002, p. 45), esta se assemelha bastante com a bibliográfica diferenciando-se por se tratar de material que ainda necessita de um tratamento analítico.

\section{A POLÍTICA DE ASSISTÊNCIA SOCIALNO CONTEXTO DO SISTEMA ÚNICO DE ASSISTÊNCIA SOCIAL}

O Sistema de Proteção Social Brasileiro, segundo Sônia Draibe (1993), ocorre entre os anos de 1930 e 1970, considerando que foi a partir desse período que o Estado brasileiro passou a desenvolver ações de garantia e substituição de renda, por meio do sistema previdenciário da assistência social, de políticas de saúde, de educação e de habitação, dividida nos seguintes períodos: a) 1931 a 1943: constituição dos Institutos de Aposentadoria e Pensão (IAPs); expansão da legislação trabalhista com a Consolidação das Leis Trabalhistas; regulação de políticas nas áreas de saúde, educação; centralização dos recursos na Esfera Federal; b) 1945 a 1964: inovações nos campos da educação, saúde, assistência social e na habitação popular; c) 1965 a 1974, fase marcada pela expansão e consolidação do sistema de proteção social, edificado no período anterior por meio da organização institucional e financeira da política social brasileira, estruturando-se, assim, um leque de instituições responsáveis pelas ofertas de bens e serviços sociais nas áreas da educação, da saúde, da assistência social e da previdência, áreas anteriormente trabalhadas. 


\section{CoMGESSSOCIENCIAESOCEEDADE

A partir da Constituição Federal de 1988, houve a definição de um novo perfil da proteção social brasileira. Assim, podemos considerar dois momentos importantes para as políticas sociais: o período pós-1930, considerado como a fase inicial da formação do sistema de proteção social; e o segundo momento, após a Constituição Federal de 1988, que amplia o padrão de proteção social configurado por meio da perspectiva de Seguridade Social.

Draibe (1993) levanta alguns princípios pelos quais o Welfare State no Brasil foi constituído, sendo caracterizado, pela centralização política e financeira no governo federal e nas ações sociais, fragmentação institucional, exclusão da população à participação política, o autofinanciamento social, privatização e o clientelismo que ainda persiste em muitos segmentos.

A evolução dos direitos sociais trabalhistas, previdenciários e de assistência social, pode observar que somente na década de 1980, como resultado de processo de mobilização dos movimentos sociais, surge uma nova perspectiva em relação ao padrão público de proteção social que passa a se constituir, pela primeira vez no Brasil, um modelo mais amplo de seguridade social, formada pelas políticas de Previdência Social, Assistência Social e Saúde.

Sem dúvida, a Constituição Federal de 1988 é um marco da transformação no modelo de proteção social brasileiro e que inaugura o que se pode denominar de universalização da cidadania. Acostumado com a noção restritiva dos grupos a serem segurados e a simetria entre contribuições e benefícios, este novo modelo deu gênese a concepções e ações solidário-redistributivas.

Nesse contexto, a Política Nacional de Assistência Social (PNAS) reconhecida como política pública pela Constituição Federal de 1988 apresenta os seguintes objetivos:

- $\quad$ Prover serviços, programas, projetos e benefícios de proteção social básica e, ou, especial para famílias, indivíduos e grupos que deles necessitarem.

- Contribuir com a inclusão e a equidade dos usuários e grupos específicos, ampliando o acesso aos bens e serviços socioassistenciais básicos e especiais, em áreas urbanas e rurais. 


\section{conGerSSOCOENCIAESOCEEDADE

- $\quad$ Assegurar que as ações no âmbito da assistência social tenham centralidade na família, e que garantam a convivência familiar e comunitária (BRASIL, 2004, p. 33).

Couto (2010) assevera que o "reconhecimento da Assistência Social como política pública e a definição de seus objetivos elencam as condições para que esse campo de atuação passe a ser considerado como de direito social" (COUTO, 2010, p. 173).

Desta feita, o público da Política de Assistência Social é reconhecido como cidadão, sujeito de direitos, em situação de vulnerabilidades e, suas ações devem ter centralidade na família garantindo o acesso a bens e serviços e o fortalecimento de vínculos familiares e comunitários.

É mister salientar que, a organização dos serviços programas e projetos desenvolvidos na Política de Assistência Social se dá em dois níveis de complexidade: básico e especial, sendo esta última subdividida em média e alta complexidade.

Na proteção social básica, os serviços são de natureza preventiva e caracteriza pelo atendimento às famílias em situações de vulnerabilidade e risco social fortalecendo os laços familiares e comunitários. O local de referência onde são ofertados os serviços de proteção social básica é o Centro de Referência da Assistência Social (CRAS).

$\mathrm{Na}$ proteção social especial de média complexidade é desenvolvido um conjunto de ações voltadas ao atendimento de famílias e indivíduos com direitos violados, em situação de risco pessoal e social por ocorrência de abuso, negligência, violência sexual, trabalho infantil, abandono, dentre outros. O local de referência para o atendimento dessas são os Centros de Referência Especializados da Assistência Social (CREAS) e a rede de serviços a ele referenciada. Em relação ao atendimento na alta complexidade, é desenvolvido um conjunto de ações voltado aos indivíduos que romperam os laços familiares e comunitários, no sentido de fortalecer projeto de vida e/ou resgatar os vínculos familiares e comunitários. $O$ atendimento desse público são as unidades de acolhimento institucional. 


\section{CoMGESSSOCIENCIAESOCEEDADE

Por fim, conclui-se que a política de Assistência Social, através do Sistema Único de Assistência Social (SUAS), vem tendo significativos avanços, como a organização das ações em níveis de complexidade e os serviços prestados com qualidade e de caráter continuado, dentre outros; na sua concretização enquanto política garantidora de proteção.

\section{A IMPORTÂNCIA DA GARANTIA DOS DIREITOS SOCIOASSISTENCIAIS PARA O EXERCÍCIO DA CIDADANIA}

Os direitos do homem, assim como a democracia e a paz, segundo Bobbio (2004, p. 1) são pressupostos mútuos e se constituem elementos de um movimento histórico, pois, [...] "sem direitos do homem reconhecidos e protegidos, não há democracia; sem democracia não existem as condições mínimas para a solução pacífica dos conflitos".

Desta forma, Bobbio (2004) considera os direitos como evoluções históricas, que nascem no Estado Moderno e indicam o progresso civilizatório humano. Desse modo, os direitos surgem e transformam-se de acordo com as necessidades dos homens, e não são, portanto, produtos da natureza, mas, sim, históricos e passíveis de mudanças e de ampliação.

Com a emergência do Estado Moderno, há a mudança na concepção da política, antes centrada na relação entre súditos e soberanos, passando a basear-se na relação Estado e cidadãos e, desse modo, considerando os direitos, principalmente, os direitos do homem, que têm seu reconhecimento firmando por meio da Declaração Universal dos Direitos do Homem, que, para Bobbio (2004), representa, pela primeira vez, na história humana, uma partilha de valores comuns a serem defendidos e alcançados por toda a humanidade, ou seja, direitos que representam a universalidade de valores.

Segundo Bobbio (2004), os direitos são divididos em quatro gerações, a saber: os de primeira geração referem-se aos direitos civis, as primeiras liberdades garantidas; os de segunda geração - direitos políticos, referente ao poder de 


\section{CONGEESSOCIENCIAESOCIEDADE

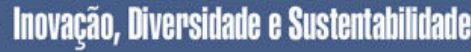

participação do Estado; os de terceira geração - direitos sociais, econômicos e culturais; os de quarta geração - direitos difusos, representados pela pesquisa biológica e genética. Esses direitos são históricos e encontram-se em constante transformação, de acordo com as necessidades humanas, para os quais devem ser criadas as condições de proteção, na atualidade, pois, somente dessa forma, é possível atingir a paz - por meio da democracia, que é o acesso dos cidadãos aos seus direitos.

Nesse contexto, os direitos civis teriam surgido no século XVIII e estariam relacionados aos "direitos necessários à liberdade individual, tais como o direito de ir e vir, liberdade de imprensa, pensamento e fé, propriedade e acesso à justiça" (MARSHALL, 1977, p. 63). A afirmação desses está associada às instituições judiciais. Salienta o autor que "os direitos civis eram indispensáveis à economia de mercado e à liberdade de concorrência, coexistindo, portanto, com o capitalismo" (MARSHALL, 1977, p. 85).

Já os direitos políticos teriam sido aqueles concebidos no século XIX, considerados como "produto secundário dos direitos civis" (MARSHALL, 1977, p.70). Esses direitos remetem à possibilidade de "participar no exercício do poder político, seja como membro eleito de um dos organismos integrantes do Estado ou como seu eleitor" (MARSHALL, 1977, p.63). Para o exercício desses direitos, há as instituições de parlamento, conselhos do governo local e congressos. Apesar de esses direitos expressarem uma participação política, não existiria uma igualdade política de fato, em razão da existência de preconceito de classe, expresso por meio da intimidação das classes inferiores pelas superiores, impedindo o livre exercício do direito do voto. Destarte, o voto secreto mostrava-se insuficiente para coibir tal prática, tornando-se imprescindível a educação social, bem como uma mudança no modo de pensar da sociedade (MARSHALL, 1977, p.85).

Por sua vez, os direitos sociais, surgidos no século XX, seriam aqueles capazes de conferir um "mínimo de bem-estar econômico e segurança ao direito de participar na herança social, bem como de acesso aos serviços educacionais e sociais. A estes estão relacionados o sistema educacional e os serviços sociais" (MARSHALL, 1977, p. 63-64). 


\section{COMEEESSOCIENCIA:SOCEEDADE \\ -}

Os direitos sociais mínimos foram desligados do status da cidadania e, por conseguinte, aquele que se beneficiasse, por exemplo, da chamada Poor Law - espécie de auxílio financeiro garantido às famílias menos favorecidas -, teria a condição de cidadão usurpada (MARSHALL, 1977, p. 72).

A evolução dos direitos do homem realizado por Marshall se dá no contexto europeu, mais precisamente na Inglaterra. No Brasil, a trajetória desses direitos (Direitos do Homem) se desenvolveu de forma diferente, havendo, assim, ênfase nos direitos sociais em detrimento dos demais, além da alteração na sequência dos direitos adquiridos, o que altera a lógica da natureza da cidadania, sendo os direitos sociais os primeiros a surgirem no Brasil, passando para os direitos políticos e, por fim, aos direitos civis.

Nesse sentido, reforçamos a colocação de Benevides, sobre os direitos que são concedidos, eles "deixam de ser direitos para serem alternativas aos direitos. Concessões, como alternativas a direitos, configuram a cidadania passiva, excludente, predominantemente as necessidades autoritárias" (BENEVIDES, 1994, p.9).

No Brasil, após uma herança histórica marcada pela escravidão e desigualdades e subalternidades, antes mesmo do efetivo exercício de direitos civis e políticos, a configuração dos direitos sociais ocorreu numa perspectiva de concessão e benesse a partir da década de 1930, ocorrendo uma fragilização dos indivíduos quanto ao exercício de sua cidadania, com significativos desdobramentos em relação à afirmação da classe trabalhadora.

Após os longos períodos de autoritarismo e de negação da participação, a exemplo do Estado Novo e da Ditadura Militar, com a redemocratização do país, no pós-Constituição Federal foi instaurado no Brasil um sistema público e participativo, como forma de oferta da política de Assistência Social, na perspectiva da garantia de direitos de cidadania.

Nesse sentido, o SUAS enquanto sistema descentralizado e participativo que regula e organiza os elementos essenciais da Política Nacional de Assistência Social (PNAS), estabeleceu normatização dos padrões nos serviços, qualidade no 


\section{COMGESSSOCEANCLA:SOCIEDADE

atendimento, indicadores de avaliação e resultado, nomenclatura dos serviços de rede socioassistencial e eixos estruturantes do sistema. Em tal sistema, os direitos socioassistenciais são um dos eixos orientadores que compõem a base de organização do Sistema Único de Assistência Social (SUAS) (BRASIL, 2012).

Por sua vez, como um sistema de gestão, esse arranjo institucional propõe, pela primeira vez na história do país, sob a primazia da responsabilidade do Estado, a organização em todo o território nacional de serviços socioassistenciais destinados a milhões de brasileiros, em todas as faixas etárias, com a participação e a mobilização da sociedade civil nos processos de implantação e implementação do Sistema.

Dessa forma, o SUAS promove uma mudança de conteúdo e de gestão da política pública de Assistência Social, ao materializar o conteúdo da LOAS e definir os conceitos e as bases que vão orientar a estruturação do sistema nos Estados, no Distrito Federal e nos Municípios. Em outras palavras, o SUAS oferece concretude à Política Pública de Assistência Social na perspectiva de construir os direitos sociais de seus usuários e sua inserção na sociedade.

Nesse processo de construção dos direitos socioassistenciais no Brasil, foi importante os conteúdos contidos na Constituição Federal de 1988, que assegurou em seu artigo 203, que "a Assistência Social será prestada a quem dela necessitar independentemente de contribuição". Isso quer dizer que todas as pessoas têm direito a Assistência Social, ela é um direito para aqueles que se encontra em situação de necessidade que, não sendo satisfeita, pode causar a ocorrência de prejuízos para a vida pessoal, social e para a capacidade das pessoas de poderem se expressar e participar de forma ativa e crítica na sociedade. Por exemplo, uma pessoa com dificuldades financeiras e sem acesso à alimentação poderá ter sua saúde prejudicada e não poderá ter a mesma vida e participação que outras pessoas.

Outro passo importante na construção dos direitos socioassistenciais foi dado em 2005, quando foi realizada a V Conferência Nacional de Assistência Social, ocorrida entre os dias 5 a 8 de dezembro de 2005, cujo tema foi "SUAS - Plano 10: Estratégias e Metas para a Implementação da Política de Assistência social no Brasil”, em que, como resultados das discussões, foram deliberados o Decálogo dos Direitos 


\section{CONGEESSOCIENCIAESOCIEDADE

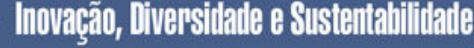

Socioassistenciais e os compromissos éticos para concretizá-los como orientadores da

Política de Assistência Social, dentre os quais, destaca-se:

a) direito em ter garantida a convivência familiar, comunitária e social: direito do usuário e da usuária, em todas as etapas do ciclo da vida, a ter valorizada a possibilidade de se manter sob convívio familiar, quer seja na família biológica ou construída, e à precedência do convívio social e comunitário às soluções institucionalizadas; b) direito à Proteção Social por meio da intersetorialidade das políticas públicas: a Assistência Social é a porta de entrada para as demais políticas públicas, como moradia digna, trabalho, cuidados de saúde, acesso à educação, à cultura, ao esporte e ao lazer, à segurança alimentar, à segurança pública, à preservação do meio ambiente, à infra-estrutura urbana e rural, ao crédito bancário, à documentação civil e ao desenvolvimento sustentável; c) direito ao cofinanciamento da proteção social não contributiva: Direito, do usuário e da usuária, à implantação e à manutenção dos serviços socioassistenciais, de caráter continuado, ofertados com qualidade, de forma profissional, garantindo o cofinanciamento nas três esferas de governo - nos meios urbanos e rurais (BRASIL, 2005, p. 313-314).

Assim, o primeiro direito do usuário da Assistência Social é o direito de ser atendido com atenção, de forma digna, e a receber explicações sobre os serviços, sobre os programas, os projetos e os benefícios da Assistência Social de forma clara, simples e compreensível.

O maior de todos os direitos da Assistência Social é o direito de todas as pessoas de terem acesso à vaga na rede de serviços da Assistência Social. Outro direito do usuário na Política de Assistência Social é conhecer a localização dos Centros de Referência da Assistência Social (CRAS) e dos Centros de Referência Especializados da Assistência Social (CREAS) para buscar atendimento e informações.

Em relação ao direito à convivência familiar e comunitária este tem uma estreita ligação com a segurança de vivência familiar ou segurança do convívio, onde pontua como "uma das necessidades a ser preenchida pela política de assistência social" (BRASIL, 2005, p.32). Nesse sentido, os serviços prestados aos usuários (as) pelas unidades da rede socioassistencial devem ser realizadas de forma a evitar o preconceito, a segregação e garantir o fortalecimento dos vínculos familiares e comunitários. 


\section{COMGESSSOCEANCLA:SOCIEDADE

Desta feita, pode-se dizer que a V Conferência Nacional de Assistência Social ao definir o Decálogo dos Direitos Socioassistenciais deu um salto qualitativo à Política de Assistência Social, pois a partir deste feito temos a clareza do papel e de quem é alvo dessa política. O direito à proteção social por meio da intersetorialidade das políticas públicas corresponde à segurança de acolhida, a qual promove o acesso do cidadão e cidadã, à rede socioassistencial através da intersetorialidade da política de assistência social com outras políticas públicas visando atendimento integral e global nas políticas. O direito ao cofinanciamento da proteção social não contributiva, esse direto extremante importante para garantir recursos, das áreas: federal, estadual, municipal e distrital, no sentido de prover os serviços socioassistenciais, com qualidade e de forma continuada.

Nesse contexto, cabe destacar que a cidadania é instituída em princípios democráticos, o qual exige organização política e participação popular nas lutas pelos seus direitos, sendo o próprio povo o responsável pelas decisões de suas vidas, quando isto acontece, através do poder do Estado, os direitos são vistos não como uma conquista democrática, mas como um favor, colocando os cidadãos numa posição de dependência.

\section{CONSIDERAÇÕES FINAIS}

No estudo realizado, observou-se que a construção do direito à Assistência Social é recente na história do Brasil, sendo estes reconhecidos como direito a partir da Constituição Federal de 1988, que inaugurou uma nova concepção para a Assistência Social por meio da propositura de um padrão de proteção social afirmativo de direito na superação do histórico de práticas laicas, caritativas e clientelistas.

Torna-se, assim, necessária a compreensão do movimento histórico em que se constrói a Política de Assistência Social e, por conseguinte, os direitos socioassistenciais como forma de apreender os limites e os desafios para concretização desses direitos, em um projeto de sociedade capitalista, que vem cada vez mais priorizando a política econômica em detrimento da política social. 


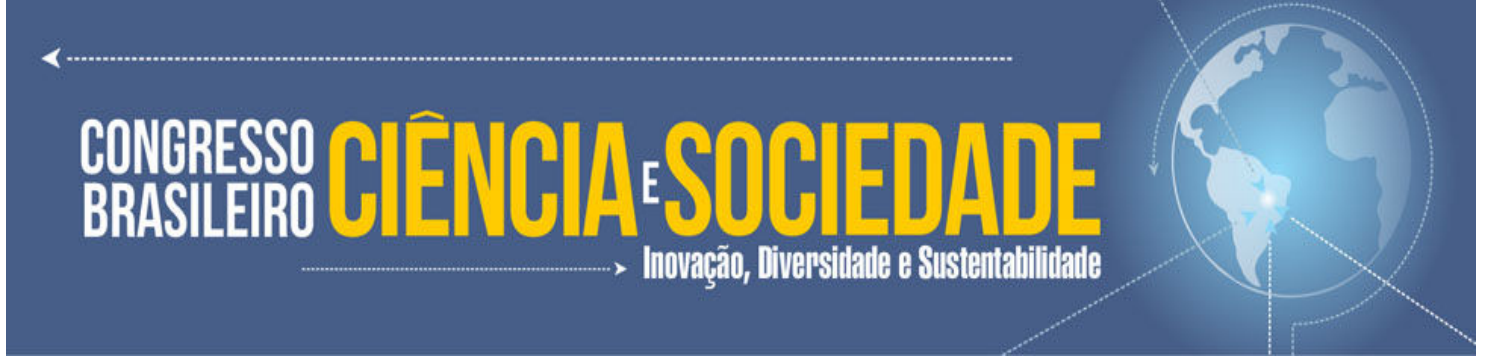

Uma questão importante também a ser ressaltada conforme Telles (1999) no estudo dos direitos sociais é a contradição entre a igualdade prevista na lei e uma realidade que apresenta uma situação de extrema desigualdade.

Destarte, conclui-se que os direitos socioassistenciais definidos, desde 2005, na V Conferência Nacional de Assistência Social na atual conjuntura brasileira, cada vez mais se tornam necessários, deixando evidente o que deve ser assegurado na política de Assistência Social rumo a uma sociedade mais justa e igualitária.

\section{REFERÊNCIAS}

BENEVIDES, Maria Victória de Mesquita. Cidadania e Democracia. Lua Nova Revista de Cultura e Política. São Paulo, n. 33, ago. 1994.

BOBBIO, Norberto. A era dos direitos. Rio de Janeiro. Campus, 2004.

BRASIL. Constituição da República Federativa do Brasil: promulgada em 5 de outubro de 1988. 38. Ed. São Paulo: Saraiva, 2006. (Coleção Saraiva de Legislação).

. Ministério do Desenvolvimento Social e Combate à Fome. Conselho Nacional de Assistência Social. Anais da V Conferência Nacional de Assistência Social. Brasília, 2005, p. 313-314

.Assistência Social, LOAS. Lei no. 8.742/1993. Dispõe sobre a organização da Assistência Social e dá outras providências. 2. ed. Brasília: MPAS/SEAS, 2001. . Ministério do Desenvolvimento Social e Combate à Fome. Política Nacional de Assistência Social -PNAS/2004. Brasília, 2005.

COUTO, Berenice Rojas. 0 direito Social e a Assistência social na sociedade Brasileira: uma equação possível? 4. ed. São Paulo: Cortez, 2010.

DRAIBE, S. M. O Welfare State no Brasil: Características e Perspectivas. Caderno de Pesquisa no 8. UNICAMP. NEEP. Editor: Marcos de Souza Queiróz, 1993.

GIL, Antônio Carlos. Como Elaborar Projetos. 4a ed. São Paulo, Atlas, 2002

MARSHALL, T. H. A. Cidadania, classe social e status. Trad. Meton Porto Gadelha. Rio de Janeiro: Zahar, 1977.

TELLES, Vera da Silva. Direitos Sociais: afinal do que se trata? Belo Horizonte: Editora da UFMG, 1999. 